\title{
Psychotherapy and emancipation
}

\author{
Paweł DYBEL*
}

\begin{abstract}
In the article I ask the question about the place of an emancipatory task within various forms of psychotherapy and psychoanalysis, where conversations with the patient play an important role. This task arises on discovering that an important source of the patient's problems are views inherited from cultural traditions, ones which inhibit a proper assessment of various traumatic situations from the past and the forms of dependence on others. Then psychotherapists and psychoanalysts are inevitably faced with the task of making the patient aware of these limitations and forms of dependence, for only then is therapeutic progress possible. I provide three characteristic examples of similar cases from Polish psychiatric tradition, in which we can speak of a similarly binding role of cultural tradition in the process of therapy. I point out that the difficult situation the therapist then finds themselves in lies in the fact that, on the one hand, they have to depart from the postulate of maintaining world-view neutrality in their approach to the patient while, on the other hand, they cannot directly impose their own position on the patient. The therapist has to find a third, middle way between these two attitudes, one which requires great sensitivity in any approaches to the patient.
\end{abstract}

\section{KEYWORDS}

psychotherapy; psychoanalysis; emancipation; cultural tradition; church; therapy process; mental disorders; conversation; dialogue

* Professor of philosophy, Pedagogical University of Cracow, Department of Philosophy and Sociology, and Polish Academy of Sciences, Warsaw. E-mail: pawedybel@gmail.com. 
But if it was speech which persuaded her and deceived her heart, not even to this is it difficult to make an answer and to banish blame as follows. Speech is a powerful lord which by means of the finest and most invisible body effects the divinest works: it can stop fear and banish grief and create joy and nurture pity. [...] The effect of speech upon the condition of the soul is comparable to the power of drugs over the nature of bodies. For just as different drugs dispel the different secretions from the body, and some bring an end to disease and others to life, so also in the case of speeches, some distress, others delight, some cause fear, others make the hearers bold, and some drug and bewitch the soul with a kind of evil persuasion.

Gorgias, Encomium of Helen (Gorgias, 1982: 52-53)

1. The dynamic development of psychiatry and various forms of psychotherapy, which began in the second half of the $19^{\text {th }}$ century, was influenced by the emergence of industrial societies in Western Europe and the United States, in which the sphere of interpersonal relations underwent profound changes. Great urban regions were created, industrial centers emerged around factories and ironworks, where work was carried out at the conveyor belt and women started to be employed on a large scale, bureaucracy developed in public and private institutions. As a result, the rhythm of metropolitan life took on an extraordinary intensity. This resulted in increasing pressure on individuals, who now had to struggle to survive in a highly competitive market environment. They also became entangled in networks of new types of professional and administrative dependence on others, forced to achieve maximum efficiency at work, etc. No wonder that leading psychiatrists and sexologists of the time, such as Richard von Krafft-Ebing, Wilhelm Erb and Willy Hellpach saw in these profound changes the source of the emergence of new types of mass mental disorders (Krafft-Ebing, 1885; Erb, 1893; Hellpach, 1902). According to them, a sign of modern times has become a growing nervousness, because the demands that living in modern industrial communities imposes on individuals lead to permanent stress, which they are often unable to cope with.

Opposing that views, Adam Wizel, a student of Charcot, one of the most eminent Polish psychiatrists of the time, argued that neuroses, especially hysteria, have accompanied people since the dawn of culture (Wizel, 1896). Therefore, they are not a particular feature of modern times. According to him this was first of all due to the development of psychiatry and psychotherapy, in which attention was drawn to various mental disorders and attempts were done to diagnose them in line with modern scientific standards. Yet, at the turn of the $19^{\text {th }}$ century, distinction was made between "somatics", who believed that mental disorders were determined solely by changes in the body (Wilhelm Griesinger, Maximilian Jacobi), and "psychics", who, referring to the tradition of German Romanticism and animism, saw mental illnesses as disturbances in the activity of the soul (Cristian August Heinroth). In France, a similar 
distinction was drawn between physical and moral therapeutic methods (Marcinów, 2018: 40-44).

In the course of nascent psychotherapy, the heiress of the "psychic" approach and moral treatment, tried to acquire knowledge about a patient's illness during regular meetings. They were asked about their ailments, professional and family relations, various pieces of advice and suggestions were given to help them cope with their own disorders and life problems. This approach to the patient was characterized by gentleness, the use of suggestions, but in such a way that the patient would not notice it. This type of psychotherapy was usually practiced in sanatoriums or hospitals, making the patient lie quietly in bed in a separate room, giving them the feeling that they were not being observed and that nothing was being forced upon them (Germ. die Bettbebandlung). From the very beginning, there were also differences in the way the talks were conducted, what they were supposed to be about. Psychotherapy was also often combined with the administering of drugs, hydrotherapy, inducing hypnosis, etc. Sometimes somatic treatments such as bloodletting or vomiting were also used.

A completely different approach to the patient was proposed Sigmund Freud, outlining at the turn of the $20^{\text {th }}$ century the foundations of his psychoanalytical theory. Abandoning hypnosis and other means used at that time, he developed his own model of therapy focused on inquiring during a dialogue with a patient as to the hidden significance of their symptoms. This model was based on the conviction that the symptoms are usually based on the patient's sexual life disorders, related to traumatic events in their youth, in which the perpetrators were invariably adults from the patient's immediate environment. The problem Freud faced during the therapy was first the patient's resistance to recalling these unconscious events, and then their resistance to criticizing the perpetrators involved in them. The patient's behaviour was often marked by the pressure of traditional forms of dependence on others and their difficulty in mentally freeing themselves from them. The very recollection of a traumatic scene from the past, in which they had been sexually exploited by someone close to them, contained in itself an element of confrontation with the cultural patterns instilled in them by their social environment and those unwritten norms on what could be said in public and what could not.

This was supported by an idyllically impeccable image of parents and adults, who from an early age should be shown respect and love. As a result, a patient who had suffered harm from one of these had to question cultural patterns and norms the awareness of which had hitherto prevented them from properly assessing this behaviour in order to work through the traumatic consequences of their behaviour. Often they did not have the courage to do so, this being combined with the fear that no one would believe their story. Anyway, the psychotherapist had to combine the patient's therapy process with their mental 
liberation from the cultural norms and patterns they had inherited. Based on these assumptions, Freud's method, grounded in the experience of psychiatry and psychotherapy at the turn of the $20^{\text {th }}$ century, initiated a "psychoanalytical movement", which with time differentiated into many factions, schools and trends.

2. It is not my aim to outline the landscape of various schools and currents of $20^{\text {th }}$ century psychiatry, psychotherapy and psychoanalysis to describe the differences between them. Neither is it my goal to comment on which forms of patient therapy therein practiced were, or are, more fruitful, and which less so. Instead, I would like to raise a number of questions relating to the emancipatory claim inherent in therapies in which conversation with a patient plays an important role. This aspect came to the fore in the Freudian model of therapy mentioned above, in which the analyst often was confronted with patient resistance to recall the traumatic events from their past in which they had been sexually abused, and then with resistance to criticizing the perpetrators. The patient's therapy began then to be closely linked to the emancipation of their cultural and social self-consciousness from the norms and patterns stemming from tradition.

I think that this emancipatory moment is inherently contained in each model of psychotherapy that proceeds as conversation with the patient. The psychotherapist here is often confronted with a situation in which the forms of dependence on others inherited from the cultural tradition make it impossible for the patient to overwork their own traumatic experiences and free themselves from mental disorders and symptoms. These forms of dependence, behind which certain views and ideas instilled in them by their social environment stand, block them mentally, and often prevent them from confronting themselves directly with the factual meaning of any traumatic events that took place in the past.

The psychotherapist's task is then to make the patient overcome these resistances and blockages, which often implies direct or indirect confrontation with the cultural patterns and values behind these social forms of dependence on others. Naturally, in psychotherapy, this emancipatory claim may not always appear. Everything depends on the type of sources of the patient's mental disorders and on their character. Yet, in many cases of neurotic disorders and in some psychoses the psychotherapist is forced to undertake this emancipatory task, because otherwise the therapy would end in failure. Naturally, the therapist risks patient rejection of her interpretations, advice and suggestions, but this risk is inherent in the very essence of the therapeutic process.

A similar attitude of a psychotherapist is therefore based on a specific emancipatory claim. This emancipatory claim does not always have to appear, but it is potentially included in all forms of therapy conducted as a conversation. 
Often we have to deal with a situation in which the forms of dependence on others determined by cultural tradition and inherited images make it impossible for the patient to overwork their own injuries and free themselves from disorders. These forms and images, behind which certain ideas and values stand, psychologically block the patient, making it impossible for them to confront themselves directly with the actual causes of these disorders and the consequences for their psyche.

This emancipatory claim, as I said before, appeared in Freud's model of therapy. During his conversations with patients, it became clear to what extent one of the sources of their neurotic disorders are the relations rooted in the tradition of patriarchalism, dependence on others, views on sexual life, various superstitions rooted in universally accepted norms and conventions. On the basis of these experiences, the author of Totem and taboo even drew up projects for emancipation through psychoanalysis of the whole of society, but he did not bestow on these any concrete form. Later, the idea of emancipation of society through psychoanalysis would be referred to by representatives of the Frankfurt School, such as Theodor Adorno or Max Horkheimer. They would combine it with the Marxist idea of "emancipation" of society from the capitalist model of the market economy and from liberal ideology. In a similar spirit other representatives of this School, such as Erich Fromm or Herbert Marcuse, would refer to Freud's theory. A separate place in this context should be given to Wilhelm Reich, who in his work and activities was to focus on the sexual emancipation of society combined with economic emancipation from capitalism.

Jürgen Habermas, the leading representative of the so-called second generation of the Frankfurt School, in one of his early books Knowledge and buman interests (Habermas, 1972) emphasizes the moment of critical auto-reflection present in Freud's theory, which defines the methodical attitude of an analyst during the therapy process. According to Habermas, this process is not only about deciphering the distortions that make up the patient's "private language", in which they "created illusory imaginations of himself" (Habermas, 1972: 267), but also about the transformation of it into the language of "public communication" (Germ. öffentliche Sprache) that is regarded by him as a universally accepted standard. This process is also accompanied by constant critical reflection on the part of the analysts as to the methodological assumptions of their own conduct. And this is the most characteristic feature of Freud's theory, in which the constant self-reflection of analysts during analysis is identified with what is scientific. The psychoanalytical process consists not only of a reflection on what constitutes its object (the "private language" of the patient), but also of the analyst's constant self-reflection on the correctness of the process itself. In this reading of Freud's theory, the emancipatory claim that is directed at the patient's unconscious, which finds its expression in their 
distorted "private language", is closely linked to the analyst's self-emancipatory process, who at the same time takes a critical attitude in relation to themselves, to the methodical way in which they analyse the patient. Habermas undoubtedly takes a very peculiar view of the emancipatory claim present in the psychoanalytical process, maintaining that it should be applied not only to the distorted "private language" of the patient (unconscious), but also to the analyst themselves, who must constantly correct their own conduct. In his view, Freud in an extremely radical way realizes the Enlightenment's belief in the emancipatory powers of critical reason in the form of self-reflection.

This reading of Freud's theory and the model of analysis based on it, which aims to decipher the deformed "private" discourse of the unconscious of the patient and make it an element of the discourse of "public communication", i.e., commonly practiced language games, appears today as a strong simplification of the dramaturgy of the therapy process. First of all, the role of critical self-reflection both in psychoanalysis and in other forms of psychotherapy, is very limited. Secondly, it is difficult to consider the discourse of "public communication" as the ultimate goal of an analytical process in which at the end the patient's "private language" disappears, because very often precisely those values that are generally associated with this discourse are the source of the patient's problems. For example, the conviction that everything in life should be subordinated to making a career, striving for enrichment, recognizing some people as unquestionable authorities, etc. These values often turn out to be too superficial and obvious.

The task of "emancipating" a patient should be then understood in a completely different way than what Habermas proposes. It is not an emancipation in relation to one's own "deformed" private language (unconscious discourse), but in relation to the values and ideas behind the "conscious" discourse of public communication accepted by a given society. In the process of patient emancipation in analysis, the starting point and support can be only the unconscious discourse, in which the actual "problem" of the patient in a veiled way comes to the fore. There are also other factors, which have little in common with Habermas' understanding of the emancipatory process in analysis as based on the critical reflection of the patient and the constant auto-reflection of the therapist, that become crucial in the process of patient therapy. These include, for example, techniques aimed at changing the patient's attitude towards themselves and others, releasing repressed emotions (acting out), confrontation with repressed traumatic events from the past, making the patient aware of the ambiguity of what they actually said and provoking them to reflect on it, and so on.

In such a therapy, the status of the unconscious "private language" of the patient should be determined in a completely different way from what Habermas is proposing. It is not a "deformed" discourse, which is a derivative in 
relation to commonly practiced language games (public communication), but a discourse in which the actual problem of the patient, absent at the level of consciously controlled language, is revealed in an encrypted way. Therefore, to combine the patient's emancipation with the transformation of their "private language" into an element of "public communication" is simply a misunderstanding. On the contrary, the "private language" of the patient in which their unconscious repressed desires come to the fore should be recognized by its own rules, because it is within this language that the patient's actual problem is hidden. Consequently, the emancipation of the patient in relation to cultural superstitions and prejudices that define their self-understanding should consist in something completely different from including their unconscious discourse in the language of "public communication".

This is overlapping with another problem. Psychotherapists and analysts often have to deal with patients with such serious disorders that it is a serious mistake to stimulate their ability to "think critically" and to make them aware of some aspects of their own statements and behaviors that they do not notice. These patients are simply incapable of adopting a similar attitude and need to be prepared for it first, often by giving them appropriate medication.

This does not mean that in the treatment of disorderly patients we do not have to deal with situations in which stimulating critical reflection on oneself and one's references to others, as well as in relation to one's inherited views, can play an important therapeutic role. Similarly, the psychotherapist themselves is often forced to "critical self-reflection" during therapy, i.e., to correct the strategy they have chosen, depending on how the patient reacts to their words and behavior. Therefore, the importance that Habermas attaches to both these critical and reflective (self-reflective) attitudes is not entirely unjustified. However, one should be aware of their limitations, as well as of the fact that one cannot expect from every patient that during the therapy they will be able to undertake a critical reflection on themselves, and especially on their own "deformed" private discourse. At the same time, the therapy process consists of many other factors which have little in common with Habermas' understanding of it. Anyway, when a psychotherapist undertakes an emancipatory claim during therapy, they cannot at any cost allow the therapy to turn into a worldview dispute.

The situation in which the psychotherapist finds themselves then is certainly extremely difficult. They have to find a kind of third way between the requirement of maintaining distance, i.e., refraining from any evaluation of the patient's behaviour and influencing their views, and the psychotherapist's conviction, developed during therapy, that one of the obstacles in improving the patient's mental condition are the patient's false ideas about themselves and the views the patient has inherited from their cultural tradition. The way of therapy then begins to resemble a narrow path leading between Scylla's 
postulate of neutrality and Charybdis' views of the patient, that both threaten the therapy process. But anyway, it is through this path that the psychotherapist has to lead the patient, being surprised time and again by the sharp corners, the faults and the emerging traces. By entering it, kind of impossible task is undertaken, but something of this impossibility is contained in every situation of therapy.

If the psychotherapist sticks rigidly to the requirement of "neutrality", they will not be able to talk openly with the patient about those issues with which the patient has a vital problem. The therapy will then become stuck in one place, because these vital issues are methodically excluded from it. That is to say the issues that are the source of the patient's disorders - of the patient's anxiety, inhibition or depressive states. If, however, the psychotherapist tries to influence the patient's attitude and views too directly, the only effect might be enhanced patient resistance and their entrenchment within themselves. Or even the breaking up of the therapy itself. The psychotherapist must therefore find a "golden mean" between these two attitudes, being aware of that each of them involves a different kind of risk. But if the psychotherapist does not take this risk, shielding themselves from the patient with the armour of "neutrality" the psychotherapist will fail.

3. The psychotherapist who enters into dialogue with the patient opens up for the latter a space of hope to come to terms with themselves. This hope is rooted in the phenomenon of dialogue as such. For it is first of all in a dialogue with others that we confirm ourselves as subjects. This is crucial in this form of therapy. This therapeutic dimension of a dialogue was discovered by Socrates. He was convinced that a properly conducted conversation could change the interlocutors. His dialectic method was aimed not only at precisely capturing in a dialogue the meaning of the key concepts of human self-understanding. It concerned equally their life attitude. As Damian Olesiński writes:

especially in terms of the compatibility of words and deeds. This is confirmed by Plato's message that the main aim and message of the Socratic philosophical method is to test human life as an expression of concern for the soul (Olesiński, 2017: 49; trans. by P.D.).

For Socrates, therefore, elenctics was a therapy (therapeia). Not only was it aimed at changing the views of the interlocutors on a given issue, but also at changing their approach to their own lives. Not only did they have to realize that their previous views were wrong or one-sided. At the same time, they received invaluable pieces of advice, a kind of inner compass, on how to search for truth in their life and live according to it. In this way they regained peace of mind, which allowed them to cultivate their own arete by finding themselves in 
life situations. The most eloquent testimony of such an attitude was Socrates' behaviour before the court, remaining calm and steadfast throughout the trial, including the moment when he heard the verdict of death. As in Socrates' dialogue, truth is always at stake in the process of therapy that proceeds as a conversation with the patient. This is the patient's truth about themselves, connected with their own arete and self-acceptance, which, as a result of various circumstances, has been disturbed or completely lost. Naturally, these disturbances do not consist in - as is usually the case with Socrates' partners in a dialogue - the simplistic or false understanding of the given issue. They usually refer to some traumatic events from the past, to brutal violations of their sphere of intimacy, with stressful relationships of dependence on others, and so on. These factors belong to a different "category" of issues than those that Socrates discussed with his interlocutors and pose quite different challenges for the psychotherapist. In addition, compared to ancient times, there is a greater diversity of mental disorders today, and we know much more about disorders such as hysteria and schizophrenia, than did the ancient Greeks. No wonder that modern psychiatric and psychoanalytical theories classify them in different ways and recommend different strategies for dealing with them in the process of their therapy.

4. According to the Greeks, a human being should strive in their life to maintain the ideal state of harmony between the different powers of their soul, which allows them to maintain peace and control over themselves in every life situation. This state and ability were termed arete by them. Today, in our age, which seems to have become even more "agitated" than in the days of KrafftEbbing and Charcot, the range of mental disorders is much wider than it was in the days of Socrates and Plato. Therefore, obtaining the kind of harmony with oneself postulated by the Greeks, is far more difficult, if at all possible. At best, it can be perhaps conceived as the ideal target point which the psychotherapist can only partially obtain, often resorting to various kinds of compromises with the patient and the psychotherapist's own method.

However, the conviction that the self-knowledge which a human subject achieves in a dialogue with others and in which the subject finds themselves, can "heal", is inscribed deeply in the self-understanding of European cultural tradition. Contemporary psychiatry, psychotherapeutic methods, psychoanalysis are, regardless of which methods and strategies of therapy they employ, are also inheritors of this tradition. An essential part of their social legitimacy is the conviction that self-knowledge, self-insight, critical self-reflection, introspection, self-analysis are powerful means that allow human beings to regain some kind of internal balance and rid themselves of false ideas about themselves. And this regardless of the extent to which we are critical of this conviction, or point to its limitations. 
The patient's expectation that a psychotherapist or psychoanalyst will "cure" them, and thus help them to free themselves from internal blockages, symptoms and all kinds of mental disturbances, depends often on the patient's readiness to learn some "difficult" truth about themselves and others. It implies a readiness to confront oneself with oneself during therapy, even if the confrontation is painful for the patient. In this confrontation, the patient would have sometimes to question their previous image of themselves, radically change their way of living, their relationships with others, etc. Very often, however, the patients do not realize and are mentally not ready for the fact that they will have to face such challenge during therapy. They imagine their own therapy as a process that will be for them mentally painless. Just as it is when they take the medication they have paid for.

If it turns out that they would have to perform a painful operation on their own self-image, some of them may find it frustrating to such an extent that they would decide to break the therapy. In other cases, the patient's disorder may be so severe that even this initial level of readiness to follow the therapy cannot be achieved. Then the only way is to prescribe the right medications to the patient first, which will reduce the severity of their depressive state. Naturally, there is no guarantee then that the patient would be ready to collaborate with the therapist later and that their therapy would have a positive effect. Anyway, as I said above, the risk of failure is inscribed in the very essence of the psychotherapy process.

5. The process of achieving self-knowledge that occurs in therapy conducted as a dialogue, is closely related to what I have called above the emancipatory claim on the part of the psychotherapist. The patient, learning some truth about themselves, i.e., realizing the nature of their own dependence on others, being conscious of the mechanism behind their narcissistic fantasies, confronting the exaggerated moral requirements that block their behaviour, etc., is ready to free themselves from all these determinants and constraints. Because these are often rooted in patterns, norms and values that are typical for the given cultural tradition any emancipation from them is equivalent to emancipation from these patterns, norms and values.

We have arrived at the key question of our considerations: in what situations does the psychotherapist's task to cure the patient entitle them to arouse in the latter the critical attitude towards some patterns of behaviour, ways of thinking, norms and values that are widespread in a given society? Does not this emancipatory approach go too far and involve a violation of the privacy sphere of the patient's life? Doesn't the psychotherapist risk then, in addition, that the patient's current conflicts with others will be overlaid with new conflicts with them for whom these cultural patterns of behaviour, norms and values are (still) binding? 
Eli Zaretsky in The secrets of the soul, reflecting on the reasons for the popularity of Freud's therapeutic method in Western societies, maintains that its focus on exploring the personal unconscious of the patient faced the processes of freeing the subject from the pressure of family relationships and traditions (mass migrations of population in search of work) typical for the second industrial revolution (Zaretsky, 2004). Therefore, the truth about the patient that has been revealed during the therapy, i.e., the whole sphere of repressed desires, childhood traumatic scenes, in which the perpetrators were usually adults etc., could now become the basis for one's own life decisions. And here even if they could not be accepted by the patient's social environment because they are in contradiction with commonly followed behavioural patterns and values. As a result of these aforementioned social processes, the pressure of this environment on individuals has decreased substantially in modern societies. Individuals could now begin to shape more freely their own lives, taking as the starting point of their life decisions that which was revealed during their therapy.

Simultaneously the analyst, by gaining insight into the "personal unconscious" of their patients, could encourage them to make these decisions. Thus, they could suggest breaking up with a fiancé or even divorce, to oppose pressure from parents and family; they can reassure homosexual patients that their orientation is not a perversion or sin, and so on. No wonder that psychoanalysis quickly became popular in industrially developed countries such as the United States, Germany of the 1920s, Great Britain, France, where the processes of industrialization and urbanization combined with the prevalent liberal-democratic system served to expand the sphere of individual freedoms within the cultural and social sphere. The paradox is that psychoanalysis soon became much more popular in these countries than in its birthplace, the Austro-Hungarian Monarchy and later in Austria.

However, in societies that were only on the threshold of the second industrial revolution, the situation of psychotherapists and psychoanalysts was diametrically different. The dialogical forms of psychotherapy could only be practiced without hindrance if the doctor's approach and their diagnoses did not touch upon sensitive issues related to social taboos, mainly concerning the sexual life of patients. In this respect, the situation described in Hermann Nunberg's diary, which took place in the period when he worked as an assistant at the Jagiellonian University in Krakow in the Department of Psychiatry under Professor Jan Piltz, is particularly noteworthy:

During one staff meeting, Professor Piltz was called away to the telephone; when he came back, he asked which one of us was treating a certain girl in the outpatient department. I said that I was. The girl whom I had in psychotherapy on a psychoanalytic basis, was the sister of the bishop's cook. After each session with me, she would be questioned by her sister as to what we had talked about. When her sister found out 
what we discussed, she became very upset and complained to the bishop; he in turn called up the Professor and demanded that that sort of treatment be stopped immediately. Despite the protests of all my colleagues, Professor Piltz solved the problem by taking the patient into psychotherapy himself. Such was the power of the Catholic Church in Poland at that time! (Nunberg, 1969: 13)

Leaving aside the whole farce-comic dimension of this situation, it shows tellingly how, in a society where sexuality is a taboo subject and the Church pretends to be its guardian, it is very difficult to practice a form of psychotherapy which deals with mental disorders the source of which are problems the patient has in their sex life. Not only does the patient succumb then to external pressure, but also the psychotherapist himself may be exposed to harassment. However, from the merits point of view, in this case the success of therapy was probably dependent on a change in attitude by that girl towards her own sexual life. This, in turn, implied the emancipation of her to the prevailing views on this subject in her immediate environment.

6. The second example. This stems from the work of a Polish doctor-psychiatrist, Tadeusz Jaroszyński who was not a psychoanalyst himself, but who valued the methods of Freud. The case concerns a 40-year-old married woman who suffers from anxiety neurosis. She:

comes from a relatively healthy family. [...] She lives in the countryside, she has always liked horses, she often travelled alone with a carter; a few times, when she was 18 , she let him close to her and let him touch her genital parts. 12 years ago she got married, she has two healthy children. She married without love, she was frigid in her sexual acts. After the second child (seven years ago) the patient was very exhausted by the long childbirth and the memory of the occurrence above was revived in her, her guilt assumed huge proportions in her eyes and the patient began to torment herself with remorse; she became unable to work [...].

Two years ago the occurrence with the carter was repeated, allegedly it was a superficial touch of the genital parts by the penis. At that time and later her husband used protective measures during copulation. In the last year the patient became nervous, weak, as seven years previous. But a sharp deterioration occurred when she heard from one of her confessors that using protective measures during copulation was a sin and that "for such a sin there is no absolution." From that time on, she started to think and be afraid that [she would be refused absolution]. Because of that she made her confession a few times more and although her confessors calmed her down saying that she would always get absolution, for it is not a mortal sin [...] - these thoughts and fears of being exposed to this great distress were so strong that the patient had to be sent to a sanatorium for a second time. All day long the patient was consumed by the thought that she would not get absolution, she constantly saw herself in her mind going to confess, speaking about her sin and the confessor not absolving her. Her husband promised to her that there would be no intercourse or only intercourse without protective measures, but this did not calm her down, she was not certain if it would 
be really so and despite the repeated assurances of friends and priests that confessors tolerated it if you had your doctor's permission - she constantly doubted if she might not come across a confessor who would be relentless in this respect.

At the same time, the old occurrence with the carter was revived in the patient's memories, and especially the last such event (two years ago), and also in this context she started to be tormented by thoughts and uncertainty if this occurrence was adultery or not. She constantly pictured this moment, how this encounter looked, whether it had been full copulation or not, if seduction was possible at all in this position; to resolve this doubt, she did a number of "trials" with her hands, legs, torso, imagining the circumstances of this moment and wanting to assure herself that there was no full copulation after all. She calmed down for a moment, but then uncertainty was sparked again and the patient again checked in her thoughts and through simulation if copulation couldn't have taken place. Repeated persuasion and explanations to the patient that her fears were unfounded, for copulation was impossible in these conditions and the question of absolution was repeatedly resolved, were not enough for the patient; she often said that "her doubt is stronger than logic" and that she knew very well that her scruples were unjustified, and yet she was unable to chase away the thoughts haunting her and to order herself not to be tormented by them. This state lasted for a few months, the patient was also treated internally and through physical procedures; she completed treatment with some signs of improvement (Jaroszyński, 1913: 269; trans. P.D.).

On reading the account of this case from over a hundred years ago, it is hard not to reflect on how many women in Poland face similar dilemmas today. As far as contraception is concerned, the position of the Church has not changed in any way, and what is more, using the in vitro method to conceive a child is considered a grave sin. In the context of our considerations, this case is particularly significant, because in a way we see in it the extent to which the source of mental disorders can lie in the instance of a severe Freudian superego implanted in the subject by religious cultural tradition.

Naturally, we do not know all the circumstances that led to the patient's anxiety neurosis. Yet, one of them was certainly a marriage crisis aggravated by the limited sexual life of both spouses. It is also worth noting that this woman's sense that her early sexual experiences were to be qualified as premarital infidelity, appeared after she was exhausted from giving birth to a second child and when she had not obtained absolution from the priest. For this woman this was an additional powerful blow. The lack of absolution meant her being stigmatized as a sinner who deserves hell.

There is no doubt that in order to free this woman from the excessive sense of guilt, which was the source of her constant self-incriminations, the psychotherapist would have to attempt to change her rigorous attitude towards her own sexual behaviour. But then he would have to question the judgment of the priest-confessor who had qualified it as a grave sin. This, in turn, would entail the necessity of questioning the whole teachings of the Church regarding 
sexual life and the use of contraception. It seems, however, that in the case of this deeply disturbed patient, a similar approach would have had little chance of success. The scale of her disorder proves that when other confessors gave her absolution for using contraception, she was unable to rid herself of her dilemmas, fears and doubts.

Another therapeutic strategy would probably be to make the patient aware of the scale her marital crisis and to point out its causes in her emotional frigidity towards her husband. From this case account it is clear that she did not love her husband and her sexual life with him gave her no satisfaction. Her fleeting affair with the carter being largely the result of this. Therefore, to come to terms with herself, she would have had to change her attitude towards her marriage, and towards her sexual expectations as well. But this in turn would have required making life decisions that were in contradiction with the Church's teaching (divorce) and which would not have been accepted by her social environment. In this case the patient's deep neurosis was clearly influenced by views derived from her religious tradition. How, then, should a psychotherapist approach this situation in which therapy success depends clearly on changing a patient's attitudes to the teachings of the Church and to her views on her own sexual life? For it is clear that otherwise she would not free herself from her doubts, dilemmas, and fears. On the other hand, however, it would be extremely difficult to bring about change in this case during therapy, since the patient's views on all the issues mentioned above seemed to be deeply ingrained in her.

This case shows us how an approach to human sexual behaviour rooted in a particular religious tradition can be one of the important factors influencing the mental disorders of patients. Therefore, a psychotherapist dealing with such cases cannot fail to refer to this approach during therapy and not try to change it. With this in mind, a psychotherapist cannot fail to criticise the cultural context in which therapy takes place. But how can they do this without risking being immediately criticized and rejected by the patient? After all, there is no ready-made theory or method, which would reliably indicate it to a therapist, how to proceed in similar cases, because each case is unique. The choice of the appropriate therapeutic strategy by a psychotherapist towards a patient is first of all a matter of practical knowledge called by Aristotle phronesis, not theoretical knowledge.

That is why a psychotherapist cannot express during the therapy any critical position directly and try to authoritatively impose it on a patient. All depends on their sense of how to make the patient aware of their problem. In a word, it is about awakening with skillful interventions, interpretations and suggestions the critical sense in the patient themselves. Emancipation in therapy is above all the self-emancipation of the patient who due to the skillful strategy of the psychotherapist begins to realize the mental mechanisms that block and 
disturb them and that are often rooted in a given cultural tradition determining their self-understanding.

7. And the last example. This concerns a patient of Adam Wizel's, a certain Miss M. After therapy she gave him her diary, in which she described her youthful experiences, first in her family home and then in a Catholic Gymnasium. In 1926 Wizel published a large part of this diary with his own extended commentary (Wizel, 2001). In her diary, Miss M. devoted a lot of attention to her own schizophrenic fantasies, which were centered around the obsessively recurring idea that she should offer humanity some exceptional good that would be universally useful. She imagined that this would be the birth of a child, which would be the other Christ, the savior of humanity. M.'s description of her own family situation shows that she was a child emotionally abandoned by her parents and left to herself. This was a source of her strong sense of guilt, her conviction that there was something particularly bad and sinful about her by nature. During her stay in the Catholic Gymnasium, she tried to compensate for this by striving for absolute spiritual perfection and becoming a holy woman, which was also supposed to be a kind of antidote to her unrealized sexual desires and fantasies. In his commentary, Wizel points out that Miss M., even when she began to have an obsessively schizophrenic fantasy of being the second Mother of God, felt that "something was wrong with her". So when she realized that confessing her own problems and obsessions to the priests did not give her anything because they were unable to help her, she finally turned to him as a psychiatrist.

8. The case of Miss M. shows how the symbolism of a given cultural tradition, in this case the symbolism of Catholicism, combined with the symbolism of Polish Romanticism, is used by disturbed patients in order to cope with their own life problems. The peculiar combination of these two traditions is reflected in the following statement of Miss M.:

I will not wonder whether the Romantics were right to consider Poland as a chosen nation or not. What do I care, what is said and written about it now? I will do my job, I will give the world a man as big as the world, and I will show women what the word "mother" means. I stand firmly, I lean against Poland as a whole, because despite everything I believe that I am not an accident in my nation. I do not know who he will be, what horizons he will discover for humanity, whether he will conquer heaven or earth. [...] So let it be so, that I was born too late by a hundred years, but I will tear you away, I will extort it from you, I will extort it from the Universe, a piece of your divinity, and I will curse it in the body of my son... Oh, my son, my son, choose your father yourself, and make sure that I am not mistaken, and that whoever he is, whether he is a husband or a lover, or whether he will be a master, a peasant, whatever (Wizel, 2001: 119-120; trans. P.D.). 
Miss M. compensates for her own low self-esteem by imagining herself as a woman "chosen" to fulfill the great mission of giving birth to a son, the future Saviour of Poland and of the world. For this purpose, she uses a biblical story about the peculiar circumstances of the birth of Christ by the Mother of God, a central female figure within the religious symbolism of Christianity, combining it in a strange way with the romantic concept of Poland and Poles as a "chosen nation". At the same time, she imagines herself as a woman who, like Our Lady, is pure love and, in addition, a mother-parent who gives humanity someone special, finds in the economy of her mental life a counterbalance to the painfully felt lack of love on the part of her parents and the long-awaited man.

Wizel's commentary shows that the patient's awareness of the psychological mechanism that led to the creation of a set of schizophrenic fantasies in the course of therapy allowed her to free herself from them. In this case, the process of patient emancipation patient in relation to the way in which she began to build her new identity as a holy woman turned out to be therapeutically effective. It is also worth noting that Wizel's description and interpretation of this case, in which he exposed the schizophrenic character of the patient's identification with the Mother of God, was strongly criticized by conservatively oriented psychiatrists, who saw it as a kind of sacrilege, sometimes adding clear anti-Semitic accents to their criticism.

The case of Miss M. is another proof that a psychiatrist is often confronted with situations in which they have to take a specific position on the way in which their patients use a symbolism functioning within the framework of a given culture. Often, as in the above case, this is a religious symbolism. But it may well be the symbolism underlying the discourse of a given ideology, political programme, various types of symbolic systems used today by the Internet mass-media. Mentally disturbed patients often reach for elements of this symbolism, giving them a pathologically distorted form in their world. Or they unconsciously reveal something deeply morbid contained in the symbolism underlying a given ideology. As in the case of a schizophrenic patient of Roman Markuszewicz who:

stated that mentally ill are in reality healthy people. They only pretend sickness in order to receive from the State, free housing and upkeep. Because of this they have a great deal of free time, and occupy themselves by sending out of their bodies atmospherically polluted rays. My informer felt endangered by these rays. That is why he proposed poisoning the psychiatrically ill in order to cleanse the atmosphere (Markuszewicz, 1976: 8).

In order to cleanse the social atmosphere, it is therefore necessary to get rid of those superfluous people who are threatening us and who are fraudsters. In 
the $20^{\text {th }}$ century, similar views formed the basis of the ideology of two states, whose leaders took them literally and murdered tens of millions of people. Today, in many different versions, they are returning in the statements of populist politicians, but under different slogans and symbols. And there are also those who take them literally. As in the case of the murderer of the Mayor of Gdańsk, Paweł Adamowicz. ${ }^{1}$ His killer can naturally be psychiatrically qualified as a sick man with schizophrenic fantasies. However, what can we say about politicians who, through their statements, provoked and provoke similar behaviour? Or about a large part of society who thinks in a similar way? What is health and what is mental illness here? What is normalcy and what is schizophrenic madness? How can one qualify it at all? Do such forms of behaviour even undergo medical treatment?

In such cases, what would the therapy be like? How can one free a subject from thinking of others as "essentially" better and worse? As those of whom some of their essence would be the incarnation of good, while others would be the incarnation of evil? And that is why they should be stigmatized? How is emancipation from aggression possible in such cases? How should a psychotherapist, who in their practice is confronted with similar quasi-schizophrenic views, behave in this situation? Are they supposed to methodically exclude them from the therapy process if they are clearly connected with political ideology or a particular religious tradition? Should the therapy process be isolated from what is happening right outside the psychotherapist's surgery window if they are dealing with a similarly thinking patient? Or if their patient has a panicky fear that they are going to be excluded by their social environment? As in the case of the married woman who did not receive absolution?

What is the responsibility of the psychotherapist in this case? Is it merely only professional or is there something more in it? Are psychotherapists not often confronted with situations in which they have to engage their own views in the therapy process and relate the therapy to the socio-cultural context in which it takes place? Are they not sometimes simply forced by the behavior and statements of the patient to undertake some sort of emancipatory mission with the firm conviction that this is the only way to help the patient overcome their own problems and fears? As in the case of Socrates, who not only taught his interlocutors how to understand the concepts that lie at the basis of their selfunderstanding, such as truth, justice, beauty and goodness; but at the same time, he taught them how to live according to their own arete. And it was for this that Socrates was convicted.

${ }^{1}$ On 13 January 2019, Adamowicz was stabbed during a live charity event in Gdańsk. He died on the following day from his injuries, at the age of 53. The assassin was apprehended at the scene of the crime. He proved to be a former inmate, who had been released from prison a month prior to the assassination. 


\section{BIBLIOGRAPHY}

Erb, W. (1893). Über die wachsende Nervösität unserer Zeit. Heidelberg: Universitäts Buchdruckerei von J. Hörnig.

Gorgias. (1982). Encomium of Helen. (D.M. Macdowell, Trans.). Bristol: Classical Press.

Habermas, J. (1972). Knowledge and buman interests. (J.J. Shapiro, Trans.). Boston: Beacon Press.

Hellpach, W. (1902). Nervösität und Kultur. Berlin: Verlag von Johannes Räde.

Jaroszyński, T. (1913). Przyczynek do nauki o psychonerwicach. Kraków: Drukarnia Uniwersytetu Jagiellońskiego.

Krafft-Ebing, R. (1885). Über gesunde und Kranke Nerven. Tübingen: Verlag der Luppschen Buchhandlung.

Marcinów, M. (2018). Historia polskiego szaleństwa. Gdańsk: Słowo/Obraz, terytoria.

Markuszewicz, R. (1976). A Miraculous Escape. Beecroft: John Hammond.

Nunberg, H. (1969). Memoirs, Ideas, Reflections. New York: The Psychoanalytic Research and Development Fund.

Olesiński, D. (2017). Elenktyka jako therapeia w świetle Platońskiego Eutyfrona (pp. 49-59). In: K. Łapiński, R. Pawlik \& R. Tichy (Eds.). Therapeia, askesis, meditatio. Praktyczny wymiar filozofi $w$ starożytności $i$ średniowieczu. Warszawa: Wydawnictwo Uniwersytetu Warszawskiego.

Wizel, A. (1896). Wiek nerwowy w świetle krytyki. Warszawa: G. Centnerszwer.

Wizel. A. (ed., intro. \& comm.). (2001). Pamiętnik pacjentki. (D. Danek, Rev. ed.). Kraków: Universitas [ $1^{\text {st }}$ ed.: 1926].

Zaretsky, E. (2004). The secrets of the soul. A social and cultural bistory of psychoanalysis. New York: Vintage Books. 